\title{
Relações de Gênero e Matemáticas: entre fios e tramas discursivas
}

\section{Relations of Gender and Mathematics: about discursive threads and tissues}

\author{
Maria Celeste Reis Fernandes de Souza ${ }^{1}$ \\ Maria da Conceição Ferreira Reis Fonseca ${ }^{2}$
}

\begin{abstract}
RESUMO
Neste artigo experimentamos teorizações foucaultianas na análise do material empírico de uma investigação sobre configurações das relações de gênero nas práticas matemáticas de catadoras e catadores de materiais recicláveis, com idades compreendidas entre 18 e 76 anos, pertencentes a uma Associação de Catadores, e que participavam de um projeto de Educação de Pessoas Jovens e Adultas (EJA). Operando com a noção de discurso, interpelamos a razão de matriz cartesiana e o sujeito da razão para mostrar como, em meio a tensões discursivas, relações de gênero e matemática são produzidas e encontram-se implicadas na constituição das subjetividades daquelas mulheres e daqueles homens, catadoras e catadores, alunas e alunos da EJA, e na naturalização de desigualdades de gênero.
\end{abstract}

Palavras-chave: relações de gênero; Matemática; discurso.

\begin{abstract}
In this paper we experience Foucaultian theorizations to analyze empirical material from a research about configurations of gender relations in mathematical practices of male and female collectors of recyclable materials, aged between 18 and 76, participants in an Association of Collectors, attendants of an Adult and Young Education Project (Educação de Pessoas Jovens e
\end{abstract}

DOI: $10.1590 / 0104-4060.38464$

1 Universidade Federal de Sergipe. São Cristovão, Sergipe, Brasil. Av. Marechal Rondon, s/n, Jardim Rosa Elze. CEP: 49100-000.

2 Universidade Federal de Minas Gerais. Belo Horizonte, Minas Gerais, Brasil. Av. Antônio Carlos, 6627. Faculdade de Educação, Campus da Pampulha. CEP: 31270-901. 
Adultas - EJA). By operating with a notion of discourse, we interpellate the Cartesian reason and the subject of reason, in order to show how relations of gender and mathematics are produced, entangled in discursive tensions, and are implicated in the constitution of subjectivities of those men and those women, male collectors and female collectors, male adult students and female adult students, and how they are also implicated in the naturalization of gender inequalities.

Keywords: Gender relations; Mathematics; discourse.

\section{Cenas}

\section{Cena Um}

A convite da professora, catadoras e catadores começam a compor com materiais recicláveis um personagem: a matemática. Uma catadora leva para compor esse personagem um recipiente de amaciante. Um catador pergunta:

Valdo: É conta, Suzana?

Professora: Para ser matemática precisa ser conta, como o Valdo falou?

Uma catadora coloca um papel, outra um pincel atômico dizendo:

Jane: Matemática tem que ter a caneta.

Aos poucos, tal personagem vai sendo composto com pincel, papel, caneta, óculos, caixas de papelão, garrafas pet, e outros materiais recicláveis.

Uma catadora coloca um copo e diz:

Gina: Meu copinho de tomar café.

Os homens colocam panfletos, chamam a atenção para os preços dos eletrodomésticos e computadores, explicam sobre pagamentos:

João: Você tem que fazer a soma pra vê quanto você pagou de juro.

E convocam as colegas:

Gildo: Vão gente: Eu coloquei essa propaganda de eletro; ô gente, pelo amor de Deus.

Uma mulher mais velha convoca as mulheres mais jovens dizendo:

Ana: Vai, minhas filhas, coloca alguma coisa. A matemática vive de tudo. Pega qualquer coisa. Até um pedaço de papel. Pega a caneta da professora.

Gildo: Posso colocar pra elas? (referindo-se a duas catadoras mais jovens)

Uma catadora que não participava da atividade chega para a catadora responsável pela venda dos vidros e diz:

Alda: Me dá o troco ali. O homem tá esperando [o comprador dos vidros que ela tinha vendido]. Quero o troco. 
O catador Gildo, o mesmo que perguntara se poderia colocar o material na escultura para as duas colegas mais jovens, levanta e coloca dois materiais explicando que estava "colocando pra elas".

Quando este retorna ao seu lugar, Ana pergunta:

Ana: Por que você tá colocando pra ela? Ela te pediu pra colocar?

Enquanto catadoras e catadores continuam compondo o personagem e explicando o que cada material tinha a ver com matemática, alguns homens brincam com as escolhas femininas, mexem com os outros homens. Em meio a essas brincadeiras, ocorre o seguinte diálogo:

Ana: Você comporta como homem.

Gildo: A senhora tá me chamando de quê? De viado?

Ao final da oficina, começam discussões entre as mulheres sobre contas na Associação. Uma catadora diz:

Marta: E nós não tava entendendo direito porque soma, soma, soma, soma... e não tava certo.

Geane: $O$ dinheiro em vez de aumentar tá diminuindo.

Cátia: A gente recebe e vai pagar umas coisas dentro de casa. A gente paga o que dá e depois... paga o que não dá. A gente faz as contas e acha que dá, mas não dá. Igual eu. Paguei o que deu pra pagar. Igual esse mês agora, e depois arrumo dinheiro pra pagar o resto.

\section{Cena Dois}

Foucault, refletindo sobre "a questão do sujeito", em um dado momento, se pergunta e, também, nos pergunta:

- O que somos enquanto parte do Iluminismo? Façamos uma comparação com a questão cartesiana: quem sou eu? Eu, enquanto sujeito único, mas universal e a-histórico - eu para Descartes é todo mundo, em todo lugar e a todo momento? (FOUCAULT, 1995, p. 239).

E continua, meio a cismar:

- Talvez, o objetivo hoje em dia não seja descobrir o que somos, mas recusar o que somos. Temos que imaginar e construir o que poderíamos ser para nos livrarmos deste "duplo constrangimento" político, que é a simultânea individualização e totalização própria às estruturas do poder moderno. (FOUCAULT, 1995, p. 239).

E Foucault nos conclama:

- Temos que promover novas formas de subjetividade através da recusa deste tipo de individualidade que nos foi imposto por vários séculos. (FOUCAULT, 1995, p. 239). 
Nas duas cenas, que se distanciam no tempo e no espaço, e que são protagonizadas por pessoas de mundos tão diferentes, encontramos fios e tramas nas quais se entrelaçam discurso, gênero e matemáticas, objeto de discussão neste artigo.

\section{Fios}

Neste artigo experimentamos teorizações foucaultianas na análise do material empírico de uma investigação ${ }^{3}$ sobre configurações das relações de gênero nas práticas matemáticas de catadoras e catadores de materiais recicláveis, pertencentes a uma Associação de Catadores, e que participavam de um projeto de Educação de Pessoas Jovens e Adultas - EJA que se desenvolvia no galpão dessa Associação, palco da cena de uma aula, que aqui descreveremos, e da qual participaram 23 mulheres e 5 homens. Na Associação constituída por 56 mulheres e 8 homens, há tensionamentos diversos instituídos por relações desiguais de gênero. Se as mulheres buscam se organizar, ainda que com tensões entre elas, de modo mais solidário e assumir efetivamente tanto o espaço da Associação, como a representação junto à comunidade e ao poder público, e também o escritório que realiza a parte contábil e financeira dessa Associação, os homens, por sua vez, procuram boicotar de diferentes modos essas ações e estão sempre prontos a questionar e desvalorizar as mulheres e os procedimentos e a lógica de produção coletiva.

$\mathrm{Na}$ intenção de compreender como se configuram as relações de gênero nas práticas matemáticas daquelas alunas e daqueles alunos da EJA, buscando as interfaces entre poder/saber/verdade, recorremos a uma das ferramentas mais operacionais que encontramos nos escritos - e nos ditos - de Foucault: a noção de discurso. O discurso é para ele uma prática, que tem lugar nos atos sociais. Nesse sentido, Foucault (2005, p. 234) retira do discurso a "soberania do sujeito", e, da linguagem, a função de representação, para mostrar que o discurso é da ordem do acontecimento. Assumindo que discursos são práticas que "formam sistematicamente os objetos de que falam" e que, embora constituídos de signos, o que os discursos fazem "é mais que utilizar esses signos para designar coisas", sendo, portanto, "irredutíveis à língua e ao ato da fala" (FOUCAULT,

3 Os instrumentos utilizados na investigação foram observação de aulas, realização de oficinas de matemática por uma das pesquisadoras e entrevistas. 
2005, p. 55), será no modo como Foucault dedicou-se à busca “desse mais" que buscaremos instrumentos para a discussão que pretendemos aqui empreender.

Ultrapassando a simples referência a "palavras e coisas", Foucault se ocupa em mostrar o discurso em funcionamento, isto é, produzindo o que chamamos $o$ real das coisas; e é por isso que dizemos que o discurso, na perspectiva foucaultiana, é produtivo. Na produção de tais realidades, o discurso em funcionamento estabelece "interfaces do saber e do poder, da verdade e do poder". (FOUCAULT, 2006a, p. 229). Esse discurso encontra seu lugar em práticas sociais nas quais múltiplos enunciados disputam espaços para se afirmarem como verdadeiros.

Por isso, as práticas matemáticas que aqui analisamos são tomadas por nós como discursivas. Isso significa compreender: que nelas se engendram, e por elas são engendradas, relações de poder/saber; que elas estabelecem, compreendem e produzem identidades de gênero; e que nelas discursos de diversos campos (da matemática de matriz cartesiana, da biologia, da psicologia, da linguagem, dos movimentos sociais, dos movimentos feministas, do direito, da pedagogia, etc.) nos dizem como são ou devem ser homens e mulheres. Propondo-se a produzir sujeitos de determinado tipo, tais discursos disputam espaços nas práticas sociais procurando afirmarem-se como verdadeiros e, desse modo, são fabricadas verdades sobre relações de gênero e matemáticas.

Nessa perspectiva, a discussão dessa produção de verdades provoca-nos a deslocamentos com relação à maneira como, de modo geral, no campo da Educação e, em especial, no da Educação Matemática, temos compreendido poder, saber e sujeito.

Não nos cabe aqui buscar um foco do poder: uma dominação dos homens sobre as mulheres, de uma matemática sobre outras matemáticas, de uma cultura escrita sobre culturas orais ou de um poder de Estado sobre os cidadãos (homens e mulheres pobres, catadoras e catadores, trabalhadoras e trabalhadores organizados em uma Associação). Nem nos cabe buscar focos de resistência - lugar da grande recusa - das mulheres para com os homens, das catadoras e dos catadores sobre aquilo que os oprime, das culturas orais em relação a culturas escritas, ou de outras matemáticas frente à Matemática. Tomamos o poder como relações de forças inscritas em campos estratégicos. Ao fazermos tal opção, compreendemos que Foucault, ao dizer que nessas relações estamos todas e todos emaranhadas e emaranhados, não está "sugerindo que não haja dominação" (DREYFUS; RABINOW, 1995, p. 204) e que nos modos como nos organizamos em nossa sociedade, os homens não tenham vantagens em relação às mulheres no espaço do trabalho ou no espaço doméstico; ou, ainda, que uma matemática tomada como verdadeira ou uma cultura escrita considerada hegemônica não se coloquem, hierarquicamente, como tendo maior valor do que outras matemáticas ou do que culturas orais, respectivamente. Não estamos dizendo, igualmente, que não 
há relações desiguais e hierárquicas entre pessoas e grupos. Estamos dizendo, sim, que, se tomarmos o poder como posse, "mantemos a ilusão de que ele é apenas aplicado de cima para baixo" (DREYFUS; RABINOW, 1995, p. 204), não nos voltando para os modos como tais relações de poder "são integráveis a estratégias de conjunto" (FOUCAULT, 2006a, p. 249), como elas atravessam as condutas diárias, os enfrentamentos e as microlutas envolvidas nas relações de gênero e matemáticas, e que acabam por preservar arranjos sociais que se conformam como situações de exclusão, discriminação entre pessoas e grupos, e relações desiguais de gênero.

Segundo Dreyfrus e Rabinow (1995, p. 131), Foucault nos oferece sobre o saber uma interpretação radicalmente nova, como o faz com o poder, na qual não "considera o saber objetivo ou subjetivo". Ele considera o saber em suas relações com o poder, como um "componente central na transformação histórica de vários regimes de poder e de verdade". (DREYFRUS; RABINOW, p. 131). Consequentemente, as relações de poder/saber constituem-se sempre em disputas políticas, ao produzirem efeitos de verdade, prestando-se, assim, a preservar hierarquias, favorecimentos diversos e lugares socialmente valorizados.

Além disso, ao declarar que não era tanto o poder que o interessava, mas “a história da subjetividade" (FOUCAULT, 2006b, p. 63), Foucault nos ajuda a compreender um pouco melhor como a temática do sujeito, que nos interessa de modo especial nesta discussão, perpassa seu percurso investigativo.

Ao mostrar em suas pesquisas como o sujeito é fabricado, Foucault descentra o sujeito cartesiano, mostrando que não é o cogito cartesiano - penso, logo existo - que institui o sujeito, mas o discurso como uma prática. Logo, "o ‘sujeito' não passa de um efeito do discurso e do poder”. (SILVA, 2000, p. 102, aspas do autor). Demarcar esse deslocamento com relação ao sujeito da razão para aproximar-nos de um sujeito em constituição pela linguagem parece-nos crucial no tratamento das relações de gênero e matemáticas.

\section{Tramas}

$\mathrm{Na}$ identificação das relações de gênero em práticas matemáticas, procuramos operar apoiando-nos nas práticas. Compreendemos, entretanto, que tais práticas, "não são pura e simplesmente modos de fabricação de discursos. Ganham corpo em conjuntos técnicos, em instituições, em esquemas de comportamento, em tipos de transmissão e de difusão, em formas pedagógicas que, ao mesmo tempo, as impõem e as mantêm". (FOUCAULT, 1997, p. 13). Por 
isso, ao trazermos aqui uma das muitas cenas que compõem o material empírico da investigação que fizemos, o que pretendemos é analisá-la conformada por diferentes práticas, nas quais se constituem (e que são constituídas por) relações desiguais de gênero e matemáticas.

\section{"É conta, Suzana?"/ "Matemática tem que ter caneta"/ "Matemática vive de tudo!"}

Essas três enunciações pinçadas da interlocução que flagramos na Cena $U m$ ajudam-nos a tecer uma reflexão sobre discursos que permeiam toda a cena e que se confrontam, ora reforçando-se uns aos outros, ora tensionando e sendo tensionados, no jogo das formações discursivas a que se relacionam e que ali se atualizam, produzindo verdades sobre matemáticas e gênero.

Produzem-se verdades sobre matemáticas, quando Valdo 4 questiona Suzana, que colocara um frasco vazio de amaciante para "compor a matemática": “É conta, Suzana?". Na censura à ação da colega de trabalho, Valdo estabelece aquilo que é e aquilo que não é matemática e desautoriza a transgressão à sua classificação que, supostamente universal, não demanda por isso uma enunciação anterior que a estabeleça: "matemática é conta". Reafirma-se, assim, um modo de pensar a matemática, reforçada não apenas pelas abordagens escolares, mas por um conjunto de discursos que reiteram a força da quantificação como modo de descrever o mundo e de analisar e avaliar demandas e possibilidades, que conduz a universalidades e certezas e que suspeita do que não obedece ao que é por tais certezas estabelecido.

É nessa suspeita que, em outras tantas cenas, catadores e catadoras dirão: "Você tem que fazer a soma pra ver quanto você pagou de juro" (João); "E nós não tava entendendo direito por que soma, soma, soma, soma... e não tava certo" (Marta); "O dinheiro em vez de aumentar tá diminuindo" (Geane); "A gente faz as contas e acha que dá, mas não dá" (Cátia). A posição que assumem nessas enunciações admite que essa quantificação, constituída por uma racionalidade de matriz cartesiana, normatiza o mundo e permite que se façam previsões ancoradas na aposta de que pessoas e coisas se submeterão aos argumentos quantitativos e ao funcionamento de acordo com a racionalidade que os rege.

Essa racionalidade institui-se na pretensão de "unificar todos os conhecimentos humanos a partir de bases seguras, construindo um edifício plenamente

4 Os nomes aqui utilizados são fictícios. 
iluminado pela verdade e, por isso mesmo, todo feito de certezas racionais". (GRANGER, 1983, p. VII). Como corolário da instituição dessa racionalidade, produz-se o sujeito da razão, "único, mas universal e a-histórico", como descreve Foucault na entrevista que apresentamos na Cena Dois.

Enunciando uma pergunta retórica ("É conta, Suzana?"), ou estabelecendo um procedimento como norma ("Você tem que fazer a soma pra ver quanto você pagou de juro"), Valdo e João reafirmam discursos da razão - de matriz cartesiana - que impregnam os modos de organização e valoração do conhecimento matemático na sociedade moderna: a matemática da razão. Podemos encontrar a força dessa matemática, por exemplo, na relevância que assumem os indicadores quantitativos divulgados por governos e outras entidades, salientados pela mídia, os quais, muitas vezes, nos abstemos de analisar ou questionar e que são assumidos como critério ou justificativa para diretrizes e políticas públicas; no contexto escolar, de modo muito especial, identificamo-na na supervalorização do lugar da disciplina Matemática e na determinação pouco flexível dos modos válidos de se pensar e fazer matemática na escola.

A crítica foucaultiana ao pensamento cartesiano dirige-se às suas raízes metafísicas, que, de certa forma, justificam a anulação das diferenças e a universalização das semelhanças. A matemática serve, pois, ao projeto de "tornar a natureza mecânica e calculável" (FOUCAULT, 1999, p. 78), instituindo-se como "a ciência das igualdades, portanto, das atribuições e dos juízos, [...] a ciência da verdade". (FOUCAULT, 1999, p. 102).

A instituição de modos válidos de se fazer matemática, entretanto, não está imune aos tensionamentos que lhe interpõem as razões da vida: "E nós não tava entendendo direito por que soma, soma, soma, soma... e não tava certo" (Marta); "O dinheiro em vez de aumentar tá diminuindo" (Geane); "A gente faz as contas e acha que dá, mas não dá" (Cátia). Nessas enunciações, se há decepção por não se verificarem as hipóteses fiadas naquela racionalidade ("A gente não tava entendendo direito...", "em vez de aumentar...", "acha que dá... mas não..."), há também interpelação que a confronta com outras racionalidades que, informadas pelo que é vivido, denunciam a incongruência entre o valor do trabalho e de seu produto, põem em disputa as diferentes interpretações de como a renda da Associação é gerada, distribuída e controlada pelas "contas do escritório", e se concretizam na sobrevivência com orçamentos domésticos insuficientes.

As contas da Associação são contas feitas a caneta (afinal "Matemática tem que ter caneta"), e, como tal, se impõem como modo válido de fazer matemática, justificado pela força da cultura escrita, que potencializa os valores da racionalidade cartesiana (exatidão, certeza, rigor, linearidade, generalidade, previsibilidade, recorrência, controle, universalidade). Numa sociedade gra- 
focêntrica, a razão de matriz cartesiana argumenta, veicula-se e se reforça em mídias e modos escritos, permeando práticas, inclusive, e particularmente, as práticas matemáticas de maior valorização social.

Na cena, ainda que tensionados pela incompatibilidade dos resultados que produzem em relação ao que é vivido por aquelas mulheres, os modos escritos de fazer matemática continuam sendo narrados como de maior valor, numa hierarquia que é defendida pelos homens à medida que fortalece diferenciações de gênero que os privilegiam: entre objetos para compor o personagem, eles elegem os panfletos com propagandas que veiculam preços e condições de pagamento, para os quais eles chamam a atenção, justificando sua escolha e mostrando sua expertise na compreensão das informações veiculadas.

A escolha das mulheres, por sua vez, recai sobre objetos variados, ligados a práticas (matemáticas) domésticas, muitos dos quais remetem a operações de medição demandadas pelo cuidado da casa e pela gestão dos recursos (parcos) disponíveis: amaciante, copinho de café, garrafas pet, etc. Algumas catadoras, entretanto, intimidam-se e não ousam interferir naquela "composição da matemática". São, todavia, incitadas pelos homens, que as desafiam ("Vão, gente: Eu coloquei essa propaganda de eletro; ô gente, pelo amor de Deus") e por uma das mulheres mais velhas, que as incentiva ("Vai, minhas filhas, coloca alguma coisa") e as autoriza ("A matemática vive de tudo. Pega qualquer coisa"), questionando a interdição aos modos outros de produzir e narrar a produção matemática que não os já socialmente valorizados.

\section{"Posso colocar pra elas?"/ "A senhora tá me chamando de quê?/ "Quero o troco!"}

Foucault nos diz que, em suas pesquisas, se comporta como um "empirista cego" que tateia, que fabrica instrumentos "destinados a fazer aparecer objetos" (FOUCAULT, 2006b, p. 229) que possam dar conta dos problemas e das questões que o inquietam, em uma sociedade que não se cansa de produzir "verdades".

Também nós nos propomos, neste artigo, ainda que tateando, a expor essas relações de poder/saber/verdade que têm produzido durante séculos, "desde o Iluminismo, se não antes, o conceito cartesiano de razão [...] enredado em tentativas de controlar a natureza"5 (WALKERDINE, 1988, p. 34, tradução

5 "Since the Enlightenment, if not before, the Cartesian concept of reason [...] embroiled with attempts to control nature". 
nossa) e no qual a racionalidade se faz "profundamente masculina e da qual a mulher é excluída". (WALKERDINE, 1988, p. 34, tradução nossa). Tais produções discursivas sobre razão e raciocínio, que implicam, por sua vez, a produção de um tipo de sujeito masculino, racional, diante do qual a mulher é colocada sempre em falta, não podem ser compreendidas fora das relações de gênero. Emaranhadas nesse modelo de razão cartesiana e do sujeito da razão, produzem-se verdades sobre mulheres e homens, que inserem condutas apropriadas ao masculino e ao feminino, características masculinas e femininas, modos de raciocínio masculinos e femininos, desejos e aspirações masculinas e femininas, e que acabam por fabricar $a$ matemática como um reduto masculino. A razão cartesiana não é neutra (como pretende) com relação ao gênero e, em racionalidades específicas, desdobra-se e recobre as relações entre mulheres, homens e matemáticas.

Assim, ao nos debruçarmos sobre as enunciações que compõem aquela cena flagrada numa atividade escolar, no contexto de um projeto de EJA, num galpão de uma Associação de catadores e catadoras de materiais recicláveis, queremos compreender as práticas que as instituem como espaços de relações de poder/saber/verdade e procuramos expor as verdades que as constituem e que nelas se constituem, e que se propõem a produzir modos específicos de vida para mulheres e homens (alunas e alunos, trabalhadoras e trabalhadores, mães e pais, etc.).

Por isso, identificamos nas enunciações "Posso colocar pra elas?" (Gildo), "A senhora tá me chamando de quê? [de viado?]" (Gildo), ou "Quero o troco" (Alda) a memória de tantas outras práticas e a instauração de relações entre mulheres, homens e matemáticas que só podem ser compreendidas em um contexto discursivo que forma e conforma feminilidades e masculinidades.

Apoiado no discurso da superioridade masculina (em especial a superioridade em matemática), reforçado pela timidez de algumas colegas no desempenho da tarefa proposta pela professora ou na suposta inadequação das escolhas das outras para a caracterização do personagem matemática, Gildo se arvora a "colocar pra elas", naquela composição, objetos, segundo ele e seus colegas homens, mais adequados ao cumprimento da tarefa, porque mais relacionados à Matemática.

Ana, que é mais velha que as e os colegas, e é também muito atuante na Associação e no movimento social que reúne catadoras e catadores do país ${ }^{7}$, confronta a iniciativa de Gildo: "Por que você tá colocando pra ela? Ela te pediu pra colocar?". Em seguida, também ecoando discursos sobre modos de ser homem (e modos de ser mulher), Ana critica a atitude do colega: "Você comporta

6 "[...] profoundly masculine without the intervention of a woman".

7 Cf. $<$ http://www.movimentodoscatadores.org.br>. 
como homem". A crítica, porém, oportuniza o reforço desses discursos à medida que permite a Gildo naturalizar seu gesto de homem, reiterando verdades sobre diferenças de gênero, padrões de comportamento e matemática: "A senhora tá me chamando de quê?"

Práticas matemáticas que acontecem em espaços diversos (casas, escolas, trabalhos, ruas, associações, etc.) aparecem conectadas a modos de organização específicos nesses espaços, às relações entre as pessoas, às relações de gênero, ao trabalho remunerado e ao trabalho doméstico (não remunerado), à subsistência, à educação das filhas e dos filhos, à maternidade. Nesse sentido, não é possível voltarmo-nos para tais práticas sem compreendê-las como ligadas a estratégias de conjunto, em racionalidades específicas que se ligam ao Estado, à mídia, à justiça, à família, à Matemática de matriz cartesiana, ao Ministério da Educação, enfim, a toda uma rede discursiva que se propõe a ditar para mulheres e homens padrões de vida e modos de comportamento.

É a consideração dessa ligação que nos faz reconhecer que operar com uma concepção de sujeito consciente, autônomo, racional, unificado, enfim, dotado de razão, seria operar com uma compreensão de sujeito perigosa para as mulheres, colocadas historicamente sempre em falta com relação a uma razão masculina (WALKERDINE, 1988, 2003) que se nutre dessa concepção de sujeito. Esse modo histórico de se narrar mulheres e homens tem sido produzido em práticas bastante específicas, ora como um sinal de preocupação para com as mulheres, ora como um modo de marcar comportamentos ideais para um masculino e um feminino, como na constituição e na mobilização de práticas matemáticas como as que analisamos neste texto. Com este estudo, procuramos, por isso, desconstruir esse modo de compreender o sujeito que, desde sua instituição, tem produzido a irracionalidade como própria da natureza da mulher e a razão como inerente à natureza do homem.

Nessa perspectiva o questionamento da razão cartesiana problematiza, em consequência, não apenas um tipo de matemática narrado como a matemática, mas também a fabricação de um sujeito universal (autônomo, racional, consciente, masculino) e o modo como esse ideal da razão se propõe a produzir sujeitos de determinados tipos. Considerando que o que se denomina sujeito masculino e feminino é um modo de produção que procura fixar tipos de sujeito masculino e feminino como identidades masculinas e identidades femininas, nosso estudo procura, pois, desconstruir essa noção de sujeito, para compreender que o que se denominam masculinidades e feminilidades é efeito de produções discursivas que se constituem nas práticas sociais.

Assim é que na constituição de práticas matemáticas, na escola e fora dela, discursos produzirão, por mecanismos diversos, diferentes posições de sujeito, diferentes identidades de gênero. 
Com efeito, nas aulas de matemática que se realizam num espaço escolar institucional e nas quais a razão cartesiana dá o tom, podemos constatar essa produção de tipos de sujeito, de modo especial, nas relações de gênero e matemática. Nesse espaço, em meio a normalizações, a formas de controle dos gestos e das vozes, ao estabelecimento e ao reforço de padrões masculinos e femininos e à valorização da razão como masculina, produz-se a mulher pior do que o homem em matemática, ou a mulher irracional e o homem racional, por exemplo.

Essa produção é constantemente reforçada pelos modos como, muitas vezes, se divulgam resultados de avaliações sistêmicas e de testes de aferição de desempenhos matemáticos escolares: “em 2012 [no Programa Internacional de Avaliação de Estudantes - PISA], os meninos do Brasil marcaram 18 pontos a mais em matemática do que as meninas, em média; essa diferença entre os sexos é maior do que a média da OCDE, e manteve-se estável desde 2003"8. (OCDE, 2012, não paginado, tradução nossa).

Tais divulgações, em geral, se fazem sem se questionar o tipo de racionalidade que impregna os modos de se pensar matemática que sustentam a elaboração desses testes e os modos como se educam meninas e meninos, de modo geral, e particularmente, na escola, sempre incentivando uma maior desenvoltura masculina nas aulas de matemática, reiterando padrões de comportamento esperado de meninas e meninos na escola, e naturalizando diferenças nas relações com a linguagem cujos efeitos podem ser auferidos nos melhores desempenhos femininos no campo da Língua Materna. (ARTES, 2007; CARVALHO, 2013; SOUZA; FONSECA, 2010; ROSEMBERG; MADSEN, 2011).

Essa mesma produção discursiva, nós a podemos encontrar em práticas matemáticas diversas no espaço do trabalho, no espaço da casa, nos materiais divulgados pela mídia ou nas decisões da justiça, nas quais, como presa desse tipo de racionalidade, uma cultura patriarcal produz tipos específicos de sujeito: a mulher mais afetiva do que o homem, a mulher maternal, capaz de e destinada a cuidar; e o homem menos preso a emoções (racional) e, por isso, menos capaz do que a mulher de cuidar, mas, ao mesmo tempo, mais capaz (do que a mulher) de controlar o espaço físico e social e de cuidar da mulher. Produzem-se, do mesmo modo, a mulher aluna da EJA e o homem aluno da EJA, a mulher trabalhadeira e o homem trabalhador, ao mesmo tempo em que se fabricam padrões de comportamentos masculinos e femininos.

Nessa produção discursiva, relações de gênero e matemáticas são fabricadas e tensionadas. A enunciação de Alda - "Quero o troco..." - coloca na

8 "In 2012, Brazilian boys scored 18 points higher in mathematics than girls, on average; this gender gap is larger than the OECD average, and remained stable since 2003". 
cena aquela mulher catadora que havia, recentemente, assumido o escritório da Associação e que, portanto, passara a organizar seus aspectos financeiros referentes à venda de material, compra de materiais de consumo, pagamentos diversos, cálculo de horas trabalhadas por dia de cada associado/a e o pagamento mensal correspondente, após serem auferidos os lucros da Associação pela equação receita/despesas. Essa enunciação, demandada e autorizada pela função que Alda assume na Associação, tensiona o discurso da maior competência masculina em matemática.

Daquela atividade escolar de "compor a matemática" - em que mulheres (e não os homens) eram silenciadas ou restringiam-se a acrescentar à composição objetos de uso doméstico - participavam mulheres responsáveis pela organização da Associação, mulheres que coordenavam equipes de trabalho, mulheres que se dedicavam a vendas de materiais específicos (vidro, papel, papelão, etc.), mulheres que trabalhavam no escritório. É a uma dessas mulheres, que não se manifestara durante a atividade, que Alda se dirige para que pudesse entregar-lhe o dinheiro para fazer o troco. O posicionamento de Alda e o assumir das mulheres os espaços decisórios na Associação, nos quais critérios, decisões e relações matemáticas encontram-se implicadas, nos remetem novamente à questão do sujeito, como nos propõe Foucault.

Compreendemos, desse modo, que podemos ser mais livres do que pensamos e podemos identificar, nas práticas matemáticas, relações de gênero e matemáticas que sugerem invenções, reexistências, possibilidades de vida. É nesse sentido que pluralizamos, também, a palavra matemática, pois a vida exige outras práticas matemáticas, produzindo outras relações de gênero e matemáticas, que confrontam a supremacia matemática masculina e a supremacia de uma matemática escrita.

Cabe, por isso, considerar a força do movimento social das catadoras e dos catadores, das quais essas mulheres, organizadas em Associação participam, e que se propõe a produzir outros modos de existência para mulheres e homens, trabalhadoras e trabalhadores. No movimento ecoa, junto a outros discursos, o discurso feminista - dos direitos da mulher - que também se propõe a produzir outras formas de existência para as mulheres, na construção de relações de gênero igualitárias. Assim, outras produções de feminilidades e masculinidades reexistem à produção cartesiana, à ficção do sonho da razão, ou a uma cultura patriarcal. É como se ouvíssemos aqui o ecoar do que Foucault nos diz na entrevista, reeditada na Cena Dois: "Temos que promover novas formas de subjetividade através da recusa deste tipo de individualidade que nos foi imposto há vários séculos." (FOUCAULT, 1995, p. 239). 


\section{Alinhavos}

A análise que empreendemos neste texto, no qual tramamos discurso, relações de gênero e matemáticas, nos faz pensar nas condutas de mulheres e homens, descritas naquela cena que tem lugar em uma aula, que acontecia em um espaço diferente - um galpão de uma Associação de catadoras e catadores de papel e materiais recicláveis - mas que se constituía como uma sala de aula. A reflexão sobre o desenrolar dessa cena e de outras que foram vivenciadas por nós como pesquisadoras, e de tantas outras cenas nas quais como educadoras encontramo-nos envolvidas, nos fazem refletir sobre o espaço escolar como um espaço no qual se produzem identidades hegemônicas de gênero, e práticas matemáticas também tornadas hegemônicas em nossa sociedade. É no espaço da escola - e pelo aparato discursivo que nela circula, que ela produz e nela se (re)produz - que a matemática é constantemente fabricada como um reduto masculino, ao mesmo tempo em que se fabricam como naturais: a razão como posse do homem; e a falha, a dificuldade ou a dedicação (em geral inglória) frente a essa matemática como inerente à condição feminina.

A esse discurso da razão - que supõe um sujeito da razão - outros discursos se aliam e solidarizam-se, fortalecendo-se com ele, para continuar essa produção ficcional. Encontramos, assim, o discurso conservador machista que produz as mulheres como cordatas, solidárias, cumpridoras de normas e regras, adaptáveis; e os homens como atirados, transgressores, indomáveis (como podemos evocar no posicionamento dos homens e das mulheres na cena descrita). É esse discurso, conservador, produtor dessas verdades, que faz com que as mulheres, naquela cena, ao tomá-lo para si, não se manifestem, ou não mostrem que também conhecem e sabem jogar o jogo da matemática escolar, como o fazem Valdo, João e Gildo. Ao mesmo tempo, esse discurso autoriza e legitima que os homens mostrem como jogam esse jogo, valorizando sua destreza ao jogá-lo e se posicionando, nesse jogo, como bons em matemática.

Encontramos, também, o discurso da supremacia da matemática escrita fortalecendo a produção ficcional da mulher pior em matemática do que os homens - e nela se fortalecendo -, mas tensionando e sendo tensionado pelas práticas matemáticas que se ligam ao mundo doméstico, e prescindem do registro escrito. Portanto, os modos de se fazer matemática que se apresentam nas práticas matemáticas evocadas pelas mulheres (e pelos homens) também compreendem e estabelecem relações desiguais de gênero e matemáticas.

Por sua vez, a entrada em cena de Alda questiona o discurso da maior competência e da maior racionalidade masculina, pois elas, sim, no gerenciamento da Associação, se mostram competentes e boas de negócio. 
Retomamos, por fim, à Cena Dois, na qual Foucault nos convoca a pensar em nossas intenções e proposições educativas que, em grande parte, tendem à universalização, que ignora as diferenças (no caso específico da matemática, as diferenças de gênero), e a nos interrogar sobre os jogos de verdade que se apresentam em nossas pesquisas e práticas educacionais, nas quais cotidianamente verdades que promovem aprisionamentos diversos, e desigualdades, como as que relatamos, são reafirmadas.

\section{REFERÊNCIAS}

ARTES, A. C. A. Indicador nacional de alfabetismo funcional - 2001: explorando as diferenças entre mulheres e homens. Educação e Pesquisa, São Paulo, v. 33, n. 3, p. 561-580, set./dez. 2007.

CARVALHO, M. P. de. Teses e Dissertações sobre gênero e desempenho escolar no Brasil (1993-2007) - Qual o lugar das famílias? In: ROMANELLI, Geraldo; NOGUEIRA, Maria Alice; ZAGO, Nadir (Orgs.). Família \& Escola: novas perspectivas de análise. Petrópolis, RJ: Vozes, 2013. p. 61-82.

DREYFRUS, H.; RABINOW, P. Michel Foucault: Uma trajetória filosófica para além do estruturalismo e da hermenêutica. Rio de Janeiro: Forense, 1995. 299 p.

FOUCAULT, M. O sujeito e o poder. In: DREYFRUS, H.; RABINOW, P. Michel Foucault: Uma trajetória filosófica para além do estruturalismo e da hermenêutica. Rio de Janeiro: Forense, 1995. p. 231-249.

FOUCAULT, M. Do Governo dos vivos. In: FOUCAULT, M. Resumo dos cursos do College de France. Rio de Janeiro: J. Zahar, 1997. p. 101-106.

FOUCAULT, M. As palavras e as coisas: uma arqueologia das Ciências Humanas. 8. ed. São Paulo: Martins Fontes, 1999. 541 p.

FOUCAULT, M. A arqueologia do saber. 7. ed. Rio de Janeiro: Forense Universitária, 2005. $236 \mathrm{p}$.

FOUCAULT, M. Problematização do Sujeito: Psicologia, Psiquiatria e Psicanálise. 2. ed. Rio de Janeiro: Forense Universitária, 2006a. v. 1. Coleção Ditos \& Escritos. 350 p.

FOUCAULT, M. Estratégia, Poder-Saber. 2. ed. Rio de Janeiro: Forense Universitária, 2006b. v. $4.396 \mathrm{p}$.

GRANGER, G. Descartes. In: DESCARTES, R. Discurso do Método; Meditações; Objeções e respostas; As paixões da alma; Cartas. 2. ed. São Paulo: Abril Cultural, 1983. p. VI-XXIII. 
OECD. Programme for international Student Assessmente (Pisa) Results from Pisa 2012. Paris: OECD. Disponível em: $<$ http://www.oecd.org/pisa/keyfindings/pisa-2012->. Acesso em: 20 set. 2014.

ROSEMBERG, F.; MADSEN, N. Educação Formal, mulheres e gênero no Brasil contemporâneo. In: BARSTED, L.; PITANGUY, J. (Orgs.). O progresso das mulheres no Brasil, 2003-2010. Rio de Janeiro/Brasília: Cepia/ONU Mulheres, 2011. p. 390-434.

SILVA, T. T. da. Teoria cultural e educação: um vocabulário crítico. Belo Horizonte: Autêntica, 2000. 125 p.

SOUZA, M. C. R. F.; FONSECA, M. C. F. R. Women, Men and Mathematics: A View Based on Data From The 4th National Functional Literacy Index (INAF-Brazil). In: COBEN, D. C.; O’DONOGHUE, J. (Orgs.). Adult mathematics Education: Papers from Topic Study Group 8, ICME 11 - 11th International Congress on Mathematical Education. Limerick: NCE-MSTL, University of Limerick, 2010. v. 1. p. 1-10.

WALKERDINE, V. The mastery of reason. London: Routledge, 1988. 283 p.

WALKERDINE, V. Couting Girls Out: Girls and Mathematics. Londres: Virago, 2003. $183 \mathrm{p}$.

Texto recebido em 01 de novembro de 2014.

Texto aprovado em 18 de março de 2015. 